\title{
LA EVOLUCION DE LOS PRECIOS \\ EN ESPAÑA Y EL PENSAMIENTO MONETARIO DURANTE EL SIGLO XVI. UNA NOTA *
}

\author{
MANUEL JESUS GONZALEZ \\ Universidad Autónoma (Madrid)
}

El presente trabajo tiene por objeto poner de manifiesto en qué medida y qué instrumentos de la teoría cantidad de dinero de los precios tal y como se configura en la actualidad detectaron los escolásticos españoles del xvi.

La exposición consta de tres partes. En la primera se recorren los hitos principales de la historia económica castellana durante el siglo xvi. En la segunda, se presenta una explicación monetaria de los precios utilizando la teoría del dinero actual. $Y$ en la tercera, se pasa revista a las piezas analíticas que, de la explicación actual, detectaron con alguna nitidez los economistas escolásticos.

En primer lugar, se estudia el comportamiento de la población, a la manera como acostumbran los historiadores. Seguidamente se examinan el comportamiento expansivo de la producción agrícola en la primera mitad del siglo y los reajustes y restablecimiento del equilibrio que registró la economía castellana en la segunda parte de la centuria. Se recorre, además, el mismo proceso registrado en la producción y exportación de materias primas -lana y hierro- y de manufacturas. Hay que destacar que, tanto en la producción como en las exportaciones, el período más brillante coincidió con la onda expansiva de la primera mitad del siglo. Sobre este escenario real se coloca la historia de la producción de metales preciosos en Europa y América, así como las importaciones de la Península. Se destacan igualmente la importancia de los yacimientos africanos, la producción española y las entradas europeas derivadas del comercio con Europa en la primera mitad del siglo. Sobre el mismo telón de fondo se pasa revista a la historia de la Hacienda imperial, el déficit público y su financiación, destacando la importancia de los instrumentos financieros: los juros y los asientos de los banqueros nacionales y, sobre todo, extranjeros.

Las conclusiones alcanzadas en las dos primeras partes se utilizan para articular una conjetura de corte monetario sobre la inflación del siglo xvi.

* El presente trabajo es una síntesis de la ponencia leida en las III Jornadas de Historia del Pensamiento Económico. 
Partiendo del concepto de inflación como una caída del precio del dinero, determinado, a su vez, por la oferta y la demanda, se analizan los factores que operaban del lado de la oferta y del lado de la demanda de dinero en el siglo xvi. Paso a paso se examina la quiebra del equilibrio monetario producido por la llegada de la flota cargada de metales, destacando los efectos sobre el mercado real y sobre el mercado financiero configurados en las ferias. En estas últimas se estudian los instrumentos financieros generados e intercambiados. Este esquema permite introducir las expectativas, los tipos de interés real y nominal, el comportamiento de los banqueros y público generando y absorbiendo excedentes de liquidez, que al integrarse con el sector real arrojan el perfil de precios que caracterizó la inflación del siglo.

Así, por ejemplo, se avanza la hipótesis de que en la fase de auge los banqueros prestan excedentes de liquidez proporcionados por los comerciantes, exportadores y particulares, mientras la demanda de crédito de la corona no llega a elevar los tipos de interés llamativamente. Los mercados financieros, obsesionados por la oferta de fondos prestados y la elasticidad de la oferta de bienes, permite sustanciales expansiones productivas. Pero al doblar el siglo ya la demanda de créditos de la corona había crecido muy fuertemente, elevándose consecuentemente los tipos de interés y consolidándose a su vez las expectativas inflacionistas. Parte de la liquidez excedente rebosa hacia el extranjero en forma de exportaciones de capital para financiar no sólo gastos de guerra, sino también importaciones de bienes y saca de metales (liberalizada en 1560). Tipos más allá de interés desaniman la demanda de préstamos y expulsan capital del sector productivo. Al crowding-out se une otro fenómeno nuevo: paro con inflación. Se analiza también el funcionamiento de la ley de Cassell y el specie flow mecanism. Por último, se contrastan estos resultados con las explicaciones de otros historiadores.

En la última parte pasa revista a los diagnósticos de la inflación que convivieron en Castilla durante el siglo xvi. Se distinguen dos tradiciones: la de los proyectistas, que atribuyen la inflación a una variada colección de factores, y la tradición monetaria, en la que destacan algunos doctores escolásticos, que consiguen una notable superioridad analítica gracias al método heurístico en el que habían sido educados.

Sin exagerar sus méritos como economista monetario, el caso de Molina aconsejando al rey de Portugal es paradigmático; pero de cualquier forma es necesario resaltar que los doctores escolásticos aplicaron una teoría más correcta de oferta y demanda de dinero para el estudio tanto de la inflación como de los cambios y por ello deben ser recordados. 